July 2020, VOLUME 8, ISSUE 3, 48-63

E-ISSN NO: $2289-4489$

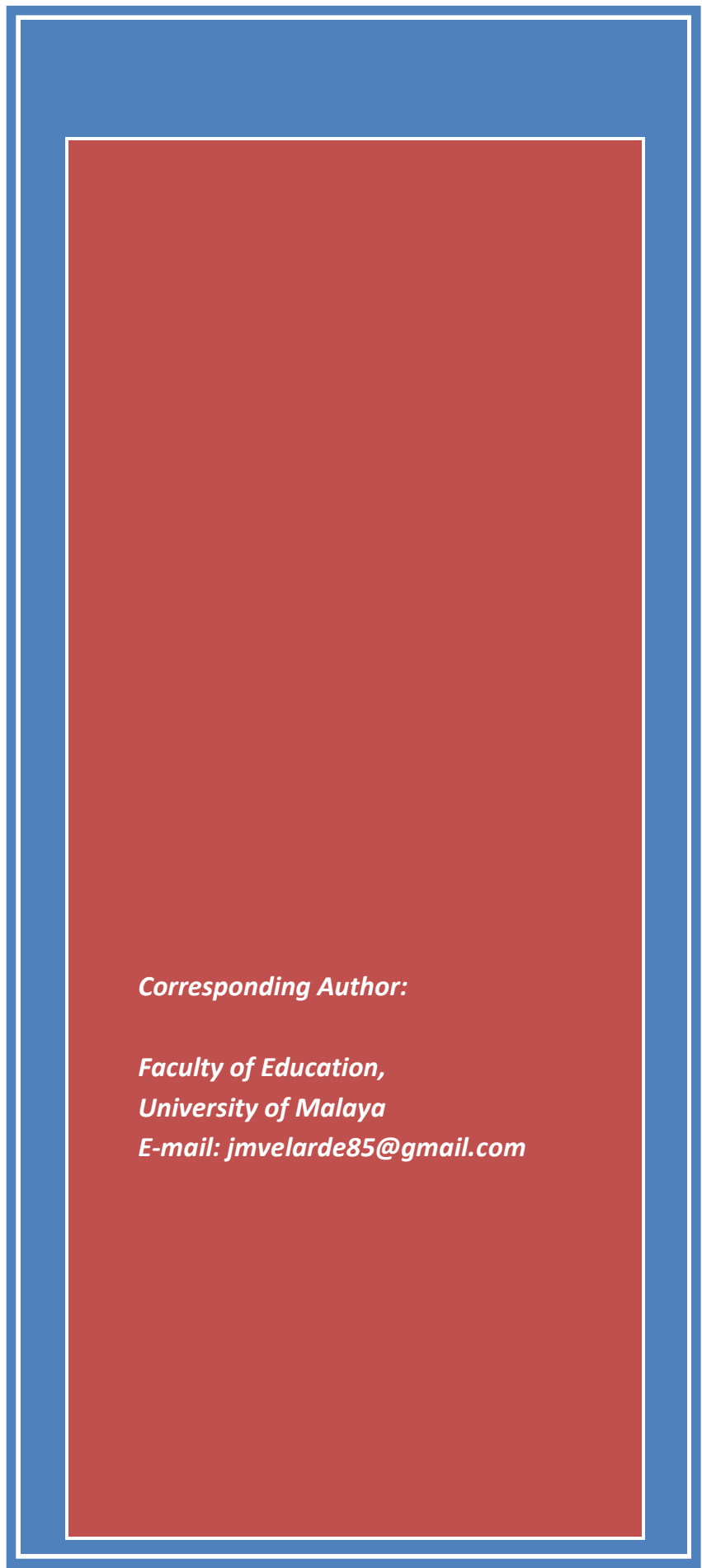

\title{
LEADERSHIP PRACTICES IN A CONDUCIVE MULTICULTURAL LEARNING ENVIRONMENT: INSIGHTS FROM NATIONAL SECONDARY SCHOOL TEACHERS
}

Joseph M. Velarde, Muhammad Faizal A. Ghani (PhD), \&

Donnie Adams (PhD)

\begin{abstract}
Building and sustaining a conducive learning environment in a multicultural setting remains to be a challenge for school leaders particularly in managing individual differences and conflicts that hinder achieving organisational goals. As such, this qualitative study aims to explore the practices, programs, and policies employed by school leaders in building and sustaining a positive learning environment in multicultural secondary schools. Nine teachers participated in interview sessions, and observational field notes were used to triangulate the responses from the interviews. The data was thematically organised and analysed using Atlas.ti. The leadership practices noted in this study revolved around the following subthemes: building an image of integrity and respect; communicating the school's mission and vision; differentiating individual needs and abilities; expressing confidence and satisfaction; supervising teachers and students. In addition, the findings also illustrated how school leaders implement school programs and institutional policies. Moreover, issues and challenges with respect to academic pressure and resource support were shared by the participants. Aside from extending the understanding of how effective school leadership could bring out a positive learning environment, this study provides a practical guide for current and future school leaders and a presentation of the current situation of secondary schools for program developers and policymakers to improve existing programs and policies on school environment improvement.
\end{abstract}

Keywords: School Leadership, Learning Environment, School Climate, Secondary Schools, Malaysia 


\section{MALAYSIAN ONLINE JOURNAL OF EDUCATIONAL MANAGEMENT (MOJEM)}

\section{INTRODUCTION}

Commonness through effective leadership brings together a multicultural learning organisation predefined by cultural and individual differences. The presence of an effective leader in a diverse organisation creates a common ground through initiatives of shared vision and values (Aldhaheri, 2017). In addition to establishing organisational goals in line with students' academic achievement, school leaders have a vital role in creating a positive environment conducive for teaching and learning (Hoy, Miskel, \& Tarter, 2013). Other than their responsibility towards their students, the influence of school leaders on teachers and stakeholders extends to bringing out collegial and amiable relationships despite the prevailing socio-cultural differences (Moolenaar, Daly, \& Sleegers, 2010; Robinson, 2007). Hence, specific leadership practices illustrate the responsibility and influence of school leaders in promoting a positive learning environment in a multicultural setting.

In defining these practices, experts agree that there is no single formula that guarantees success in achieving organisational goals as leadership roles and outcomes require proper contextualisation (Bush, 2003). At the time of this writing, literature in educational leadership and management is already flooded with prominent and emerging leadership styles with claims of effectiveness in achieving goals related to student achievement, positive school climate, teachers' motivation, etc. (Allen, Grigsby, \& Peters, 2015; Boyce \& Bowers, 2018). This saturation of leadership models leads to overwhelming insights into the best possible practices that should be filtered and narrowed down to the nature and needs of the organisation (Boyce \& Bowers, 2018). The broad nature of leadership pertaining to roles and responsibilities of an individual or a group can be limited by the extent of its effects (Bush, 2003). In specifying the school effects, focusing on building and sustaining a positive school climate in a culturally diverse learning environment contextualises the nature of school leadership practices suitable to meet this specified need.

Promoting a healthy learning environment remains to be a challenge in multicultural organisations and societies. Geographical boundaries are blurred by the open and free exchange of information through globalised, digitalised channels like the Internet (Chui \& Leung, 2014). Though this digital transformation ushers in infinite developmental possibilities, diversification continues to expand not only in terms of cultural perspectives, but also behavioural and ideological. Subsequently, the prevailing individual differences in a highly diverse society lead to social conflicts, and schools are not exempted from this. Influenced by migration patterns and the free exchange of digital information, the composition of stakeholders in learning organisations continue to be diversified, which means that different needs and expectations could lead to misappropriation, misunderstanding, and maltreatment (Sleeter \& Grant, 1987). In this seemingly chaotic world of differences, leadership provides a silver lining, and the roles of school leaders in managing differences could lead to the identification of best practices in a conducive teaching and learning environment.

Contextually, studying leadership practices in a multicultural learning environment necessitates a culturally diverse setting. Although studies in multiculturalism in education emerged in the United States due to the influx of migration in the early 1900s (Banks, 2005), a similar pattern was observed in Asian countries, such as Malaysia, due to industrialisation and commercialisation. In this case, multiculturalism in Malaysia was due to the prospect of greener pasture for migrants from India, China, and other neighbouring territories to work in rubber plantations and mines during the British Era (Abdullah \& Pedersen, 2009), and this has carried on until the modern era as Malaysia is deemed to be an ideal destination for expat workers (Harris \& Han, 2019). The responsibility of ensuring a harmonious co-existence among different people of different races, ethnicity, nationality, and religion begins with state initiatives. As such, the Ministry of Education (MOE) supports the federal government in promoting national unity through system aspirations on nation building through harmony, which is clearly stipulated in it the 2013-2025 Malaysia Education Blueprint (MOE, 2012). In terms of leadership expectations in this multicultural environment, MOE (2012) defined the need for high performing school leaders to not only address student achievement but also ensure a positive learning environment where students are taken care of 


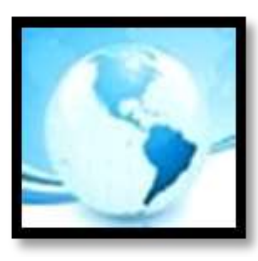

\section{MALAYSIAN ONLINE JOURNAL OF EDUCATIONAL MANAGEMENT (MOJEM)}

regardless of their race, ethnicity, or religion. Needless to say, Malaysian schools are an ideal venue in exploring effective leadership practices in creating an atmosphere of harmony and unity.

In addressing the general challenges related to promoting a positive learning environment in multicultural schools, this study aims to address the following research questions:

1. How do school leaders build and sustain a positive learning environment in multicultural secondary schools?

2. What are the programs and policies employed by school leaders to build and sustain a positive learning environment in multicultural secondary schools?

3. What are the issues and challenges faced by school leaders in building and sustaining a positive learning environment in multicultural secondary schools?

\section{Multiculturalism in Education}

From a general perspective, the notion of multiculturalism stems from the reality that societies are composed of people who are inherently and acquisitively different in terms of cultural factors such as race, ethnicity, and religion (Hofstede, Hofstede, \& Pedersen, 2012). Although Hofstede (1984) postulated that multiculturalism emanated from socio-political conceptions and polarisations, Lanzillo (2013) argued that it naturally exists in societies and organisations as an innate social condition in collective formation. Nevertheless, the current reality bound by globalised ideals draws in multiculturalism alongside its potentials and challenges, and it is the social responsibility of states to embrace cultural differences through systemic initiatives (Banks, 2005). Hence, multicultural education emanated from the awareness of the prospects and pitfalls of cross-cultural interactions in schools and communities.

Earlier studies in multiculturalism in the United States tackled conflicts of segregation and racism in an evolving pluralist society (Banks, 2005). The social tensions between races and religions cascaded into schools, which prompted educators to reform the education system to pacify inter-group conflicts and drive the community towards values of fairness and justice (Sleeter \& Grant, 1987). Similar cases were noted in Malaysia during its post-colonial era. A multi-racial and multi-religious country in Southeast Asia, Malaysia had to deal with riots between the dominant racial groups-Malay, Chinese, and Indians-during the 1960s, which prompted the government to enact a more liberal approach in nation building (Ishak, 2014). Until today, Malaysia has ensured a peaceful co-existence among its diverse citizenry through inclusive socio-economic, cultural, and education policies (Omar, Noh, Hamzah, \& Majid, 2015). The Malaysian Ministry of Education has been at the forefront of advocating multicultural values to promote national unity and harmony through academic and non-academic programs, leadership expectations, and organisational aspirations (MOE, 2012).

\section{A Conducive Learning Environment}

One of the systemic aspirations of the Malaysian Ministry of Education is to assure that all schools are fully equipped for conducive teaching and learning for all students regardless of their race or religion (MOE, 2012). In relation to the primary aim of the MOE to improve students' learning outcomes, promoting a conducive learning environment has always been supported by studies on school improvement to have a direct effect on teachers' efficacy and students' learning capabilities (Cox \& Howarth, 1990; Hoy et al., 2013). Defining a positive learning environment can be derived from the concept of school climate, which refers to organisational factors related to the quality of interaction among stakeholders, working environment, support system, and safety measures (Hoy et al., 2013). To be more precise, Hoy and Hoy (2006) proposed organisational health as a measurable construct in describing a positive school climate in terms of the level of harmony, unity, and resilience of the school as an organisation. Nevertheless, a conducive learning environment can be defined as a healthy school climate 


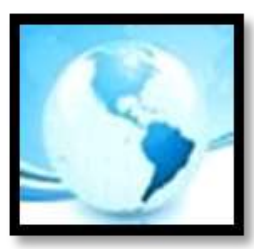

\section{MALAYSIAN ONLINE JOURNAL OF EDUCATIONAL MANAGEMENT (MOJEM)}

characterised by a strong academic emphasis, initiating structure, consideration towards members of the organisation, morale, institutional integrity, and resource support.

In studies related to school improvement and multiculturalism, promoting a conducive learning environment is as equally important as improving learning outcomes (Wang \& Degol, 2016). In Tanzanian secondary schools, an unhealthy school climate characterised by a pessimistic attitude towards teaching and learning, negative relationships among stakeholders, and unsafe atmosphere leads to low academic performance of students (Nkuba \& Massomo, 2019). In American schools, the research by Thapa, Cohen, Guffey, and Higgins et al. (2013) attributed the high level of students' academic achievement due to the commitment of district and school leaders to build and sustain a positive academic climate. In Malaysia, the government has allocated more than RM 650 million for school development and infrastructure programs, which could be highly beneficial in ensuring that every school has a conducive learning environment for better teaching and learning (NST, 2018). More than infrastructure development, a positive learning environment in culturally diverse schools could be addressed by leadership practices that promote shared values of acceptance, tolerance, and respect and that create an atmosphere of inclusivity through teaching and learning (Velarde \& Ghani, 2019).

\section{School Leadership}

School leadership has always been a critical factor in promoting a positive learning environment. The notion of leadership has evolved from the indispensable function of a central authority to the ideal responsibilities of an individual or group to drive an organisation to achieve its set goals (Bolam, 2004). As instructional leaders, principals and other appointed school leaders have the responsibility to promote a conducive learning climate by protecting instruction time, providing incentives for teaching and learning, and ensuring professional development (Hallinger, 2011). From an organisational standpoint, transformational and transactional leaders have been noted to have a direct and positive influence on creating an atmosphere of collaboration, motivation, and productivity (Avolio, 2011; Leithwood \& Sun, 2018). Furthermore, a distributed approach in school leadership enables principals to share leadership roles and management functions to capable teachers, which further builds the professional capacity of the school and the culture of learning and cooperation (Harris, 2011). From these educational leadership models, certain practices and perspectives were noted to have an impact on the learning environment especially in multicultural schools.

Based on empirical studies, instructional, transformational, and distributed leadership practices remain to be the most-widely researched in terms of their effects on the quality of the learning environment (Hallinger \& Chen, 2015; Leithwood \& Sun, 2018). Although Hallinger and Chen (2015) highlighted the high number of studies trying to correlate instructional leadership with student outcomes, they recommended shifting the focus to other school effects such as school climate. Likewise, Leithwood and Sun (2018) emphasised the significance of studying the role of transformational school leaders in building a positive learning environment in difficult school settings. In a cross-sectional study involving OECD countries, instructional and distributed leadership practices were noted to influence the way stakeholders value respect towards each other (Bellibas \& Liu, 2018). Moreover, school leaders who were consistently inspiring their teachers to work together towards the school's goals and develop their professional capabilities were reported to improve teacher satisfaction, performance, and well-being (Harmsen, Helms-Lorenz, Maulana, \& van Veen, 2018). In the Malaysian setting, school principals employing instructional, transformational, and distributed leadership were noted to drive overall school performance through inspiring innovation, collegiality, and continuous professional growth (Alwahaibi, 2019; Tajasom \& Ariffin Ahmad, 2011). Veeriah, Piaw, Li, and Hoque (2017) noted that primary school principals who registered a high level of transformational leadership had a significant effect on a positive school culture. From these studies establishing the relationship between school leadership and positive school climate, an in-depth exploration was employed by this current study to clearly illustrate how school leaders in Malaysia create a conducive learning environment amidst the challenges of cultural diversity. 


\section{METHODS}

Using an inductive approach, this exploratory study utilised a qualitative research design. From a subjectivist and interpretivist lens, the nature and dynamics of school leadership in a multicultural learning environment were explored and illustrated using data gathered from interviews and observational field notes. Creswell (2012) explained that the subjectivity of qualitative research may be deemed as a double-edged sword due to the threats of biased perceptions; however, the use of sound methodical procedures ensuring trustworthiness and credibility minimises bias.

\section{Population and Sampling}

Since the proper identification of research setting participants establishes the foundation for the trustworthiness and credibility of this study (Patton, 2015), Malaysian national secondary schools in Kuala Lumpur were selected for this study since the report from the Ministry of Education noted that national secondary schools in urban areas are more culturally diverse than their rural counterpart (MOE, 2012). Furthermore, the three selected schools were categorised by the MOE between bands 2-4, which indicated that the schools were high performing and average schools based on national key results. More importantly, these schools were purposefully selected due to the racial composition of their school population reflecting the national demography and having a culturally diverse community of teachers and students. A total of 9 teachers participated in this study, and as noted by Wang, Tan, Li, Tan, and Lim (2017), teachers are ideal sources of information with respect to educational research due to their unquestionable immersion, active participation, and multi-dimensional perspectives in describing a school phenomenon. Other than that, the following criteria were followed by the researchers in purposively choosing the teachers for the interview: at least five years of experience in the current school, regular interaction with school leaders, and knowledge of school programs or policies related to teaching and learning. Table 1 presents the demographic information of the participants. Due to confidentiality, the names of the teachers and schools were replaced with 'T1' and 'SMK1' for example.

Table 1

Demographic Information of Research Participants

\begin{tabular}{ccccc}
\hline Teacher & School & Gender & Race & $\begin{array}{c}\text { Years in Current } \\
\text { School }\end{array}$ \\
\hline T1 & SMK1 & F & Chinese & 6 \\
T2 & SMK1 & F & Malay & 13 \\
T3 & SMK1 & D & Indian & 5 \\
T4 & SMK2 & F & Indian & 24 \\
T5 & SMK2 & Malay & 5 \\
T6 & SMK3 & Chinese & 5 \\
T7 & SMK3 & M & Malay & 8 \\
T8 & SMK3 & F & Indian & 5 \\
T9 & SMK3 & & & 5 \\
\hline
\end{tabular}

\section{Instrumentation}

An interview protocol for the semi-structured interview sessions with the teachers was designed based on literature in educational leadership practices and school climate. Ten open-ended questions were formulated to solicit information about leadership practices, school programs, and policies employed to promote a positive learning environment. The interview protocol was first shared with two experts in the field of educational leadership and management to verify that the questions were in line with the objectives of the research and that 


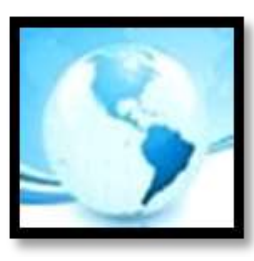

\section{MALAYSIAN ONLINE JOURNAL OF EDUCATIONAL MANAGEMENT (MOJEM)}

they were appropriate and suitable in culling in-depth responses with respect to school leadership practices in building and sustaining a conducive learning environment. For example, the following questions were used during the interview sessions:

1. How would you describe the way your school leaders lead or manage the teachers and students?

2. How do your leaders make sure that goals or expectations are met in this school?

3. In general, how would you describe the teaching and learning environment in your school?

\section{Triangulation}

In addition to the interview, an observation protocol was designed to triangulate the findings from the interviews. The initial plan for the observation protocol included a list of aims and observation points in line with the research objectives and interview findings (Cohen, Manion, \& Morrison, 2011). As such, the researchers requested permission from the principal to allow access to actual classes, on-going school activities, staff meetings, and common premises. The school principal and assistant principal also allowed the researchers to follow them while they were doing their monitoring duties and rounds to observe how they interact with members of the school community. For enhanced credibility and dependability of the study, triangulation was achieved by multiple instruments and research participants in different sites.

\section{Trustworthiness Measures}

In minimising bias and subjectivity in qualitative research, Lincoln and Guba (1986) proposed measures to ensure trustworthiness of the findings through the following criteria: credibility, dependability, confirmability, and transferability. The credibility of the findings was initially ensured in the design of the instrument and the experts' review of the open-ended questions (Cohen et al., 2011). Next, pilot studies were conducted in two schools in Klang Valley to initially test the confirmability and transferability of the responses. In this case, four teachers were interviewed to determine the clarity and structure of the interview session, and observation of classes, meetings, school activities, and surroundings were done to check the alignment of the observation objectives and the interviews. Based on the pilot interviews and observation, questions were modified to be more concise, follow-up questions were prepared, and a streamlined observation checklist was drafted.

\section{Data Collection Procedures}

Prior to collecting data, ethical procedures were followed by the researchers by obtaining permission from the university, the Malaysian Ministry of Education, the Kuala Lumpur Department Office, and the selected schools. Once permission was obtained, the researchers liaised with the assistant principals from each school to schedule the interview sessions with the teachers and the observation plan. Upon meeting the teachers, the objectives of the interview were explained, and they were assured of the confidentiality of the interview. After the teachers gave their full consent, the interview was audio-recorded. The interviews lasted for an average of 25 minutes. In addition to the interviews, observation of interactions between school leaders, teachers, and students, classroom activities, school programmes, meetings, and school surroundings lasted for a maximum of five days in every school. With the permission of the principal, photos and videos were taken, and faces or confidential information were blurred due to confidentiality.

\section{Data Analysis}

The responses from the interview sessions were transcribed in verbatim while the observational field notes were organised prior to data analysis. Following the coding framework by Creswell (2012), the findings were thematically analysed by coding segments of the transcripts, reducing the codes, and grouping these codes into subthemes and themes according to the research objectives. In ensuring credibility of the transcription and coding 


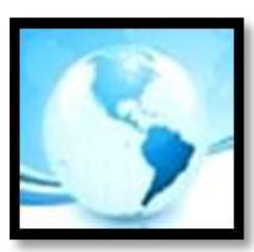

\section{MALAYSIAN ONLINE JOURNAL OF EDUCATIONAL MANAGEMENT (MOJEM)}

process, member checking was done by sharing the transcripts and codes with the interviewees. After the interviewers verified the accuracy of the transcription and the coding, external auditing was conducted as two experts in qualitative research provided their feedback on the identification and assignment of codes, subthemes, and themes. Consequently, the finalised themes and subthemes rendered from the codes and quotes will be reported in the next section.

\section{RESULTS}

From the collated responses and codes from the interview sessions, the general themes emerged in line with the objectives of this study: leadership practices, programs and policies, issues and challenges in relation to promoting a conducive learning environment in multicultural schools. For each theme, subthemes were categorised to present in detail the accounts from teachers. At the end of this section, observational field notes used to triangulate with the teachers' responses will be presented.

\section{Leadership Practices}

The teachers in national secondary schools in Kuala Lumpur reported various practices they observed from their school leaders, which they deemed effective in building and sustaining a conducive, multicultural learning environment. Their responses were organised according to the following subthemes: building an image of integrity and respect; communicating mission and vision; differentiating individuals' needs and abilities; expressing confidence and satisfaction; and supervising teachers and students.

\section{i. Building an image of integrity and respect}

The teachers acknowledged that their school leaders' disposition superseded any action that they took, and in this case, they were very particular about how their school leaders model core values of integrity and respect consistently in words and in action. Likewise, setting examples of proper decorum that reflects fairness, professionalism, caring, justice and collaboration allowed the school leaders to initiate a positive atmosphere for teachers and students to emulate. A teacher from SMK3 shared a specific action she observed about her school leaders:

“Take a very simple thing... Coming on time, punctuality... They are all punctual." (I, T9: L91-92, 31/07/2019)

In terms of gaining respect and integrity, a teacher from SMK1 related how their school leaders always showed a professional attitude in guiding them in their work:

“Whatever information that you need regarding their work, you can get it. They don't say, 'I don't know, I’m not sure.' They're not that kind." (I, T2:L59-61, 08/07/2019)

\section{ii. Communicating the school's mission and vision}

The teachers identified specific strategies and platforms wherein their school leaders communicated the school's mission and vision for the purpose of having a shared understanding and setting a common ground for the diverse members of the school community. For instance, Teacher 2 described:

"From the meeting they will state, what is our vision this year, and what the teachers are supposed to do, what facilities they can provide us to help us." (I, T2, L90-92, 08/07/2019)

In addition, the same manner was reported by the teacher from SMK3 although the focus of their mission and vision was more on students' achievement: 


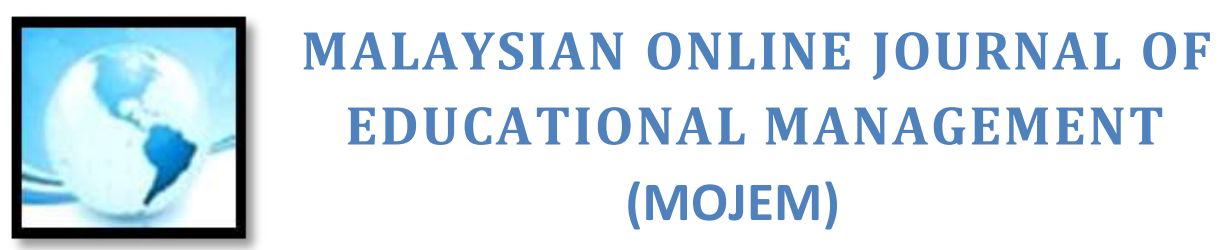

"Through meetings, academic meetings that we have once a month in order to keep us abreast of the latest development, of the progress of the students and so on..." (I, T7: L107-108, 23/07/2019)

In terms of values, the mission and vision were also used by the school leaders to advocate for harmony in a diverse environment as mentioned by the teacher from SMK 2:

"She always promotes harmony. Like, she always reminds us about unity during the assembly, during her speech. She keeps reminding us." (I, T6: L154-155, 16/07/2019)

\section{iii. Differentiating individuals' needs and abilities}

Given the naturally existing cultural and individual differences in a multicultural organisation, the school leaders had to pay attention and respond by differentiating their members' needs and abilities. In this case, the teachers noted how the school leaders investigated their religious, family, and certain personal background especially when it comes to the welfare of teachers and students. As experienced by the teacher from SMK2:

"I think should there be a problem, they call you up. They will speak to you, they will find out if it's about family or personal issues, and they will let you know the what they can do." (I, T4: L190-192, 09/07/2019)

One teacher also observed how their school leaders change their leadership behaviour based on the situation and the needs of the teachers. Teacher 9 explained:

"It's eclectic. There are times when it is a little dictatorship, when certain things are wanted, it's hard and right. Then there are times when it's laissez-faire, it's a step back. There are times when I empower you, you run it, and you be responsible for it. So, you see it in different aspects of leadership." (I, T9: L73-77, 31/07/2019)

\section{iv. Expressing confidence and satisfaction}

In motivating people of different expectations, the school leaders were observed to express their confidence to their teachers and students by using words of encouragement and giving them opportunities to showcase their skills and talents regardless of their race or religion. For instance, Teacher 3 from SMK1 shared how her principal trusts the teachers in making decisions in school:

"If it is something that requires immediate action and she can address it, she will tell me, 'I think you can do this,' or 'You can go and see the Guru Kanan Bahasa [Language Subject Head] and show this document to her and see if she has it.' And I work from there." (I, T3: L60-62, 08/07/2019)

When it comes to expressing satisfaction, one teacher shared the way their school leaders recognise their efforts in meetings:

"In the meeting, if for an individual, the principal or PK will mention the name, so at least you know, even though it is very small, but it is really deep because actually the principal realised what I have done" (I, T2:L110-112, 08/07/2019)

Other than verbally acknowledging the accomplishments of teachers, the school leaders also give rewards during annual events as elaborated by the teacher from SMK2:

"I have been rewarded like our Anugerah Cemerlang [Excellence Awards]. We have that every year. Sometimes, there's dissatisfaction but we don't know their area of contribution for us to criticize. Sometimes 


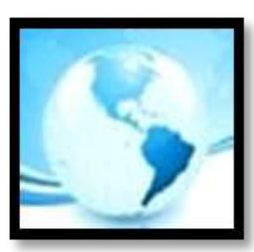

\section{MALAYSIAN ONLINE JOURNAL OF EDUCATIONAL MANAGEMENT (MOJEM)}

I think I should be rewarded but I'm not. Sometimes I think I shouldn't be rewarded but I am." (I, T4:L130$133,09 / 07 / 2019)$

\section{v. Supervising teachers and students}

In making sure that everything is running smoothly in a diverse environment, the teachers noted the importance of the presence of their school leaders, which was evident in the way they supervise their teachers and students. Physical presence is one of the ways described by the teachers:

"If we made a mistake, they will tell you. If there's an area you have to take charge with, they just tell you." (I, T4:L31-32,09/07/2019)

Other than physical supervision, school leaders also extend their presence online through social media platforms. Teacher 1 noted:

"They will make the GK [Head of Department] to lead us, to give instructions on WhatsApp group. Monitoring all the time. After 7pm, they won't WhatsApp anymore." (I, T1:L81-83,08/07/2019)

The attention given to students and their academic priorities was shared by the teacher from SMK1:

"We've just finished our midterm exams, so she's doing a 'postmortem' exercise with the students. She's getting the information from the students first because the results the students showed in the midterm exams was not very satisfying...did not meet the standard we hope they achieved, so she's calling the students what problems they encountered. She will collate all this information and present it to the teachers." (I, T3:L89-96, 08/07/2019)

\section{Programs and Policies}

The teachers from the three national secondary schools in Kuala Lumpur shared the different school programs and institutional policies they knew their school leaders implemented effectively in building and sustaining a conducive, multicultural learning environment. Their responses were organised according to the following subthemes: school programs and institutional policies.

\section{i. School programs}

The teachers identified several programs in their schools that were designed and implemented to keep a positive learning environment. In addition to celebrating festive holidays together in school, the teachers also mentioned academic and non-academic activities. For example, one of the teachers talked about academic support programs for all students in need regardless of their race or religion:

"Whatever the program already being implemented, example we have extra classes, they tell the teachers that this is to increase the achievement of the students, to increase the percentage, to get A. They ask us to work together to achieve that goal and we don't talk about races or religion there." (I, T2:L95-98,08/07/2019)

Another teacher from SMK3 observed how their school leader promoted cultural diversity in planning programs:

"Sometimes, we have motivational talk. The motivational speaker is from another race. Usually we try to get someone from another culture to come and give his or her perspectives from their culture." (I, T7: SL5:L84$87,23 / 07 / 2019)$ 


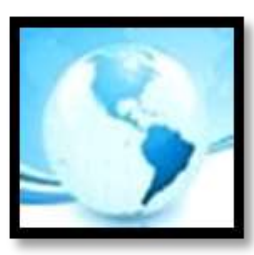

\section{MALAYSIAN ONLINE JOURNAL OF EDUCATIONAL MANAGEMENT (MOJEM)}

\section{ii. Institutional policies}

The teachers first referred to the policies from the Ministry of Education and emphasised that whatever their school leaders implement in their schools were directives from the ministry and then the department office. However, the manner of implementing these policies boil down to the school leaders, particularly the principal, as reported by the teacher from SMK2:

"Our principal has a lot of plans based on what the Ministry gives our school. If the Ministry wants to focus on harmony, our principal makes it clear to everyone here. Basically, she makes the policies straight to the point and she comes up with activities, workshops, techniques for these policies. They have a schedule and they make sure we meet the plan." (I, T6:L85-88,23/07/2019)

\section{Issues and Challenges}

Towards the end of the interview, the teachers from the three national secondary schools in Kuala Lumpur shared their insights on the issue and challenges they were facing in building and sustaining a conducive, multicultural learning environment. Generally, the teachers did not mention any issue related to inter-racial conflicts, and all of them noted how happy they were in their schools and that they could say they were in a harmonious environment. As one teacher attested:

"I think my school is very harmonious. We want to keep it like that. I do enjoy, and I appreciate seeing the students mixing around. There's not too much of 'the Malays, the Chinese'... They're not into their own sects." (I, T1:L173-176, 08/07/2019)

Despite the initiatives and actions of their school leaders in maintaining unity and harmony in the school, the teachers identified issues and challenges in the following aspects: academic pressure and resource support.

\section{i. Academic pressure}

Since a school functions as an academic organisation with institutional goals to improve students' achievement, the teachers noted the pressure coming from the Ministry, the school leaders, and the parents. As the teacher from SMK1 explained:

"Oh, academics always comes first no matter what. That's why whatever results, we have the monthly test, we have the midterm test, and every time we have the results, we have meeting, postmortem." (I, T2:L116$118,08 / 07 / 2019)$

In addition, Teacher 6 stated that it was not about the diversity of their school but the reputation of their school, which added up to the pressure:

"Academics is number one, besides the co-curriculum. SMK 2 is a brand actually. Those who know. Very popular with good results so we need to maintain the name and the status." (I, T6:L92-94, 16/07/2019)

Another teacher from SMK2 reported how parents put pressure on them and how their school leaders deal with them:

"The attendance of some students is not really very good. They have a lot of excuses why they didn't send the student to the school, which I find it is very difficult because if your child is not coming to school it's difficult to achieve. But then, parents want the achievement, and they blame the school for it, but they never send their children. That is the pressure, the only pressure. She'll [principal] give full support, she'll call the 


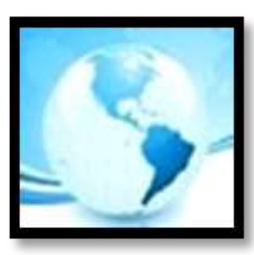

\section{MALAYSIAN ONLINE JOURNAL OF EDUCATIONAL MANAGEMENT (MOJEM)}

parent, talk to the parents. She has a very good relationship not only with the teachers, and of course with the parents." (I, T5:L123-130,16/07/2019)

\section{ii. Resource support}

Although the teachers generally thought that they have adequate teaching materials, several teachers in this study reported their schools' shortcomings in terms of resources and facilities for a better teaching and learning environment. Firstly, ICT or internet facilities were deemed to be needed and should be prioritised in schools according to one teacher:

"Everything is there. It's just time constraint. You just surf the net, you can print it out, you can sort of right away give them to students. It's just time constraint and internet connection. The school's internet is sometimes bad, so I have to use my own data." (I, T3:L204-207,09/07/2019)

In addition, a teacher from SMK3 acknowledged the fact that their school was located next to the highway and that their colonial-era buildings needed renovation, so she remarked the need for additional budget:

"I think we're a little tight of money, and that's an issue here. Many times, money is an issue. They are very thrifty. Prudence is the word. But we can still get the resources." (I, T9:L216-218,31/07/2019)

\section{Observation Results}

\section{i. Leadership Practices}

The punctuality of the school leaders was observed in all schools, and particularly in SMK1 where the assistant principal was already in her office at 6.30 am and was at the school entrance before 7 am for her morning duty (OFN, SMK1: 07.00am, 08/07/2019). In several instances in SMK2, teachers were in constant communication with the principal and assistant principal to ask them about school matters, and they were amiable and profound in responding to the teachers' queries (OFN, SMK2: 3.00pm, 16/07/2019).

When the researchers went around the three schools, murals and slogans reflecting the school's mission and vision geared towards students' academic achievement and inter-racial harmony were displayed at common areas. In one meeting in SMK 3, it was observed that the principal laid down the objectives of the meeting with respect to improving students' grades and clearly stated how this was in line with the specific goals set by the school at the start of the school year (OFN, SMK3: 2.30pm, 24/07/2019).

Since the school leaders were also teachers, it was observed in SMK1 and SMK2 how the behaviour of the school leaders varied when communicating with teachers and students in such a way that they were generally sounded more caring and endearing with students while they were threading between compassionate, professional and straightforward with teachers. Also, in SMK1, the school leader's English class had an activity where the students were divided into groups, and the school leader explained that the arrangement was planned in such a way that students can interact with each other regardless of their race and that the weaker students could get help from their classmates (OFN, SMKA: 12.30pm, 08/07/2019).

In SMK1, two post-mortem sessions took place during the observation period. The first one was with the students while the second was with the teachers. It was evident in these two meetings how the principal and assistant principal asked the students and teachers to individually raise their concerns and how dedicated the school leaders were in continuously supervising the progress of the students and the actions of the teachers to achieve their targets (OFN, SMK1: 3.30pm, 10/07/2019). 


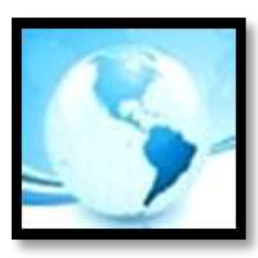

\section{MALAYSIAN ONLINE JOURNAL OF EDUCATIONAL MANAGEMENT (MOJEM)}

The kind words of the school leaders in expressing confidence and satisfaction was observed in several occasions. For instance, in a school activity in SMK3, the teachers and the students were the ones running an inter-school workshop (OFN, SMK3: 1.00pm, 23/07/2019). In a school meeting in SMK1, the principal devoted the first minutes thanking the teachers and acknowledging specific teachers who took part in giving extra classes to students. On a dedicated wall at the school entrance of all three schools, the faces of students who received top marks were displayed with congratulatory remarks. During the assembly in SMK1, the principal awarded several students with a trophy for their punctuality (OFN, SMK1: 7.30am, 08/07/2019).

\section{ii. Programs and Policies}

On display boards in different parts of the school, pictures of school activities celebrating cultural diversity were fully displayed. For instance, SMK3 had photos showing students of different races and religion taking part in Muslim, Hindu, or Chinese activities. In addition, an extra Maths class session for Form 5 students was observed in SMK1, and the class was composed of 26 students coming from different racial backgrounds (OFN, SMK1: 2.30pm, 09/07/2019).

During the assembly in SMK1, the principal used the venue to remind the students about the policies regarding coming to school on time and keeping the school clean. It was evident how the principal made the policy clear by highlighting the importance of the policy, the consequences, and the idea of collaboration or togetherness as one school in following the policy (OFN, SMK1: 7.30am, 08/07/2019).

\section{iii. Issues and Challenges}

The pressure to achieve the school's target academic results was evident in the three schools based on the displays at the entrance and common areas. For instance, in all three schools, they had a display board showing the number of days before the national exams for secondary school students. Also, in the meeting room of the schools, charts and data were posted on the wall to show their school's exam results from the previous years and their target for that particular academic year.

As observed in SMK3, it was noticeable that the classrooms facing the highway were really noisy due to the traffic and that the teachers were trying to make their voices louder to overcome the noise (OFN, SMK3: 12.30 pm, 31/07/2019). In SMK1, the researchers noticed the ICT room with only 20 computers. In terms of wi-fi connection, the school had no available connection. The teachers showed the researchers how they went online using their own phones.

\section{Triangulation of Findings}

The triangulation of the instruments and sources rendered similar themes and subthemes emerging from interview responses from the teachers and the observation field notes from the four secondary schools. Table 2 outlines the overlapping themes and subthemes culled from the interview sessions and observations that summarise this study's findings. 


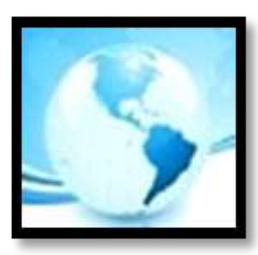

MALAYSIAN ONLINE JOURNAL OF

EDUCATIONAL MANAGEMENT

(MOJEM)

Table 2

Themes and Subthemes from Interview and Observation

\begin{tabular}{|c|c|}
\hline Themes & Subthemes \\
\hline Leadership Practices & $\begin{array}{ll}\text { - } & \text { Building an image of integrity and respect } \\
\text { - } & \text { Communicating mission and vision } \\
\text { - } & \text { Differentiating individuals' needs and abilities } \\
\text { - } & \text { Expressing confidence and satisfaction } \\
\text { - } & \text { Supervising teachers and students }\end{array}$ \\
\hline Programs and Policies & $\begin{array}{ll}\text { - } & \text { School programs } \\
\text { - } & \text { Institutional policies }\end{array}$ \\
\hline Issues and Challenges & $\begin{array}{ll}\text { - } & \text { Academic pressure } \\
\text { - } & \text { Resource support }\end{array}$ \\
\hline
\end{tabular}

\section{DISCUSSION}

The interviews with the teachers and the observational field notes illustrated a vivid depiction of school leadership practices that help build and sustain a conducive learning environment in multicultural secondary schools. What has been initially established by this study is the priority given by school leaders towards a healthy school climate in the schools in this study that were categorised as high performing and average schools. The importance of a positive school climate where students and teachers are in unity and harmony has been considered as a critical factor in the overall school improvement, as well as in the performance of students (Nkuba \& Massomo, 2019). In addition, this study has emphasised the role of school leaders in the organisational goal of multicultural schools to work towards a shared goal despite the inherent individual and cultural differences. The enduring role of leadership in organisations goes beyond the achievement of set targets as it runs deep in the fabrics of the organisation as a system of interactions among individuals of different standards and expectations (Avolio, 2011). Therefore, the leadership practices observed and shared in this study present alternative and valuable views in leading in multicultural organisations.

The nature of leadership practices specified in the interview responses can be traced back to established models in effective school leadership with regards to positive learning environment. The teachers in this study reported how their school leaders remained consistent in modelling values of integrity and respect, expressed their confidence, and differentiated needs and abilities, which sum up the distinct traits of a transformational leader. The inspirational attributes of transformational leaders in multicultural schools allow a formation of shared positive values that dilute differences in perspectives and shift actions towards achieving a common goal (Allen et al., 2015). In line with this, the distribution of instructional leadership tasks begins with expressing confidence to capable teachers (Boyce \& Bowers, 2018), which were manifested by the school leaders in this study. Furthermore, the teachers noted how their school leaders give rewards, as well supervise teachers and students. Subsequently, the school leaders function as instructional leaders whose tasks involve providing incentives and managing instructional procedures for a conducive learning environment allowing teachers to employ effective teaching practices and students to develop holistically (Hallinger, 2011). Nevertheless, testing the transferability of these practices in other multicultural schools may bring about a better understanding of effective leadership models helpful in building a positive learning environment.

Aside from the leadership practices, school programs and policies are needed to be in place for school leaders to have a basis for their actions. In this study, the teachers shared how their schools have activities that celebrate diversity, academic programs that value inclusivity, and non-academic programs that foster school unity and harmony. Although the institutional policies came from the ministry, the school leaders had the vital role in implementing these policies to cater to the needs of their school, which involved communicating the policies clearly and consistently carrying them out for the sake of having a positive environment and achieving 


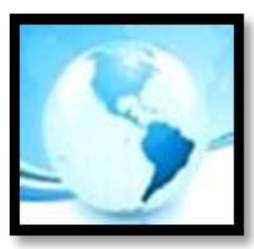

\section{MALAYSIAN ONLINE JOURNAL OF EDUCATIONAL MANAGEMENT (MOJEM)}

organisational aims (Robinson, 2007). Evidently, the programs and policies stated in this study support the aspirations of the Malaysian Ministry of Education for schools to be ideal venues of fostering unity and harmony and for school leaders to continue championing these aspirations (MOE, 2012). The alignment of practices, programs, and policies is a manifestation that the school as an organisation has a healthy environment where differences are well-managed (Hoy et al., 2013). Hence, having a positive learning environment in the context of national secondary schools is not only the responsibility of the school leaders, but also the state and other agencies through thoughtfully crafted programs and policies.

Overall, the responses from the teachers showed optimism in terms of how their school leaders helped create a harmonious learning environment; however, they were still able to identify issues and challenges such as dealing with academic pressure, as well as lacking in ICT resources and proper infrastructure. Although it was evident that multiculturalism does not have anything to do with these factors, reasonable academic goals and adequate facilities still serve as critical indicators of school climate that could impact the organisational dynamics of the school in achieving aims related to school improvement or student learning outcomes (Hoy et al., 2013; Thapa et al., 2013). Since schools are directed to improve teaching and learning as indicated by test results, pressure from various stakeholders to achieve the set targets is inevitable, so it depends on the way the school leaders handle such pressures and provide a support system for teachers and students to dissipate the surmounting pressure and convert it to a shared vision (Leithwood \& Sun, 2018). With regards to the ICT resources and infrastructure, the allocated budget of the Malaysian Ministry of Education should be prioritised towards providing schools with reliable internet connectivity and check the physical environment of the schools. A fully conducive learning environment can only be achieved when the physical environment of the school is in harmony with its organisational atmosphere.

\section{CONCLUSION}

In a positive learning environment, leadership practices matter alongside sound school programs and policies that embrace cultural diversity, balance academic aspirations, and provide reasonably adequate resources. Although this study has provided an in-depth exploration of practices, programs, and policies that school leaders employ to build and sustain a positive learning environment in performing schools in an urban setting, future studies may explore this phenomenon in other contexts and research settings that could provide valuable perspectives in effective leadership. Correlational studies can also give a generalisable view between emerging leadership models and school climate factors that were identified in this study for further examination. At this point, current and aspiring school leaders may refer to the practices of the principals, assistant principals, and heads of department shared by their teachers in this study, and think about how they can apply these practices in their schools to avoid conflicts due to cultural differences and build bridges to achieve greater aims. Furthermore, governments should continuously support school initiatives in forging unity and harmony through a conducive learning environment by initiating meaningful programs and by increasing funding for better facilities fit for this digital age.

\section{REFERENCES}

Abdullah, A., \& Pedersen, P. B. (2009). Understanding multicultural Malaysia: Delights, puzzles and irritations. Malaysia: Pearson.

Aldhaheri, A. (2017). Cultural intelligence and leadership style in the education sector. International Journal of Educational Management, 31(6), 718-735.

Allen, N., Grigsby, B., \& Peters, M. L. (2015). Does leadership matter? Examining the relationship among transformational leadership, school climate, and student achievement. International Journal of Educational Leadership Preparation, 10(2), 1-22.

Alwahaibi, S. S. O. (2019). Transformational leadership: A review on contemporary issues. International Journal of Academic Research in Business and Social Sciences, 9(3), 1399-1413. 


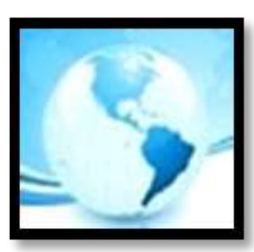

\section{MALAYSIAN ONLINE JOURNAL OF EDUCATIONAL MANAGEMENT (MOJEM)}

Avolio, B. J. (2011). Full range leadership development. London, United Kingdom: SAGE.

Banks, C. A. (2005). Improving multicultural education: Lessons from the intergroup education movement. New York, USA: Teachers College Press.

Bellibas, M. S., \& Liu, Y. (2018). The effects of principals' perceived instructional and distributed leadership practices on their perceptions of school climate. International Journal of Leadership in Education, 21(2), 226-244.

Bolam, R. (2004). Educational administration, leadership and management. Educational Management, 2(1), 17-21.

Boyce, J., \& Bowers, A. J. (2018). Toward an evolving conceptualization of instructional leadership as leadership for learning: Meta-narrative review of 109 quantitative studies across 25 years. Journal of Educational Administration, 56(2), 495-509.

Bush, T. (2003). Theories of educational leadership and management. England: Sage Publications.

Chui, W. H., \& Leung, E. W. (2014). Youth in a global world: Attitudes towards globalization and global citizenship among university students in Hong Kong. Asia Pacific Journal of Education, 34(1), 107-124.

Cohen, L., Manion, L., \& Morrison, K. (2011). Research methods in education. New York, USA: Routledge.

Cox, T., \& Howarth, I. (1990). Organizational health, culture and helping. Work \& Stress, 4(2), 107-110.

Creswell, J. W. (2012). Educational research: Planning, conducting, and evaluating quantitative and qualitative research (4th ed.). Boston, USA: Pearson.

Hallinger, P. (2011). Leadership for learning: Lessons from 40 years of empirical research. Journal of Educational Administration, 49(2), 125-142.

Hallinger, P., \& Chen, J. (2015). Review of research on educational leadership and management in Asia: A comparative analysis of research topics and methods, 1995-2012. Educational Management Administration \& Leadership, 43(1), 5-27.

Harmsen, R., Helms-Lorenz, M., Maulana, R., \& van Veen, K. (2018). The relationship between beginning teachers' stress causes, stress responses, teaching behaviour and attrition. Teachers and Teaching, 24(6), 626-643.

Harris, A. (2011). Distributed leadership: Implications for the role of the principal. Journal of Management Development, 31(1), 7-17.

Harris, A., \& Han, A. (2019). 1Malaysia? Young people and everyday multiculturalism in multiracialized Malaysia. Ethnic and Racial Studies, 43(5), $816-834$.

Hofstede, G. (1984). Culture's consequences: international differences in work-related values. Beverly Hills, USA: Sage Publications.

Hofstede, G. J., Hofstede, G., \& Pedersen, P. B. (2012). Exploring culture: Exercises, stories and synthetic cultures. Boston, USA: Intercultural Press.

Hoy, A. W., \& Hoy, W. K. (2006). Instructional leadership: A research-based guide to learning in schools (2nd ed.). Boston, USA: Pearson.

Hoy, W. K., Miskel, C., \& Tarter, C. J. (2013). Educational Administration: Theory, Research, and Practice (9th ed.). New York, USA: McGraw Hill.

Ishak, M. M. (2014). The Politics of Bangsa Malaysia: Nation-Building in a Multi-ethnic Society. Kedah, Malaysia: UUM Press.

Lanzillo, M. L. (2013). Multicultural society in Europe: Beyond multiculturalism. In M. A. Carpenter \& S. Goncalves (Eds.), Diversity, intercultural encounters and education (pp. 41-45). New York: Routledge.

Leithwood, K., \& Sun, J. (2018). Academic culture: A promising mediator of school leaders' influence on student learning. Journal of Educational Administration, 56(3), 350-363.

Lincoln, Y. S., \& Guba, E. G. (1986). But is it rigorous? Trustworthiness and authenticity in naturalistic inquiry. In D. Williams (Ed.), Naturalistic Evaluation (pp. 73-84). California, USA: Jossey-Bass.

MOE. (2012). Malaysia Education Blueprint 2013-2025. Retrieved from http://www.moe.gov.my/userfiles/file/PPP/Preliminary-Blueprint-Eng.pdf

Moolenaar, N. M., Daly, A. J., \& Sleegers, P. J. (2010). Occupying the principal position: Examining relationships between transformational leadership, social network position, and schools' innovative climate. Educational Administration Quarterly, 46(5), 623-670.

Omar, N., Noh, M. A. C., Hamzah, M. I., \& Majid, L. A. (2015). Multicultural education practice in Malaysia. 


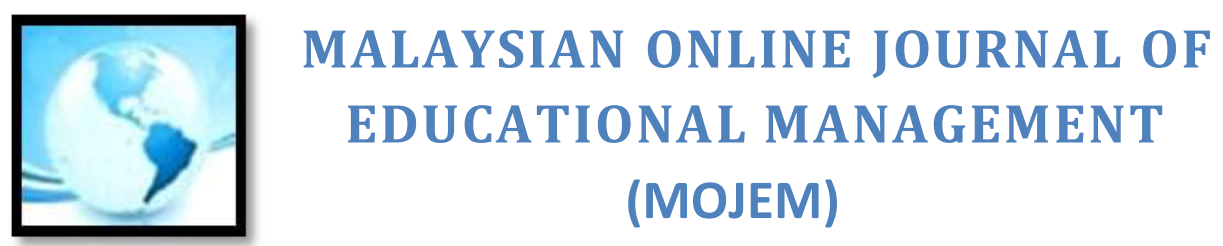

Procedia-Social and Behavioral Sciences, 174, 1941-1948.

Nkuba, L. L., \& Massomo, S. M. (2019). School climate and its influence on public secondary schools' performance in Mvomero district, Morogoro, Tanzania. Asian Journal of Education and Social Studies, 4, 1-11.

New Straits Times. (2018, November 2). 2019 Budget: RM60.2bil to be spent on education. News Straits Times. Retrieved from https://www.nst.com.my/news/nation/2018/11/427590/2019-budget-rm602bil-be-spenteducation

Patton, M. Q. (2015). Qualitative research \& evaluation methods: Integrating theory and practice (4th ed.). US: Sage Publications.

Robinson, V. (2007). The impact of leadership on student outcomes: Making sense of the evidence. The Leadership Challenge-Improving Learning in Schools, 5, 12-16.

Sleeter, C., \& Grant, C. (1987). An analysis of multicultural education in the United States. Harvard Educational Review, 57(4), 421-445.

Tajasom, A., \& Ariffin Ahmad, Z. (2011). Principals' leadership style and school climate: Teachers' perspectives from Malaysia. International Journal of Leadership in Public Services, 7(4), 314-333.

Thapa, A., Cohen, J., Guffey, S., \& Higgins-D'Alessandro, A. (2013). A review of school climate research. Review of Educational Research, 83(3), 357-385.

Veeriah, J., Piaw, C. Y., Li, S. Y., \& Hoque, K. E. (2017). Teachers' perception on the relationships between transformational leadership and school culture in primary cluster schools. MOJEM: Malaysian Online Journal of Educational Management, 5(4), 18-34.

Velarde, J. M., \& Ghani, M. F. A. (2019). International school leadership in Malaysia: Exploring teachers' perspectives on leading in a culturally diverse environment. MOJEM: Malaysian Online Journal of Educational Management, 7(2), 27-45.

Wang, M. T., \& Degol, J. L. (2016). School climate: A review of the construct, measurement, and impact on student outcomes. Educational Psychology Review, 28(2), 315-352.

Wang, L. Y., Tan, L. S., Li, J. Y., Tan, I., \& Lim, X. F. (2017). A qualitative inquiry on sources of teacher efficacy in teaching low-achieving students. The Journal of Educational Research, 110(2), 140-150. 